\title{
INVESTIGATION OF WEAR MECHANISM IN BALL BEARINGS LUBRICATED BY A BIO-LUBRICANT
}

\author{
Dedison Gasni ${ }^{1 *}$, Ismet Hari Mulyadi ${ }^{1}$, Jon Affi ${ }^{1}$, Andrea Yulandra Miswar ${ }^{1}$ \\ ${ }^{1}$ Department of Mechanical Engineering, Faculty of Engineering, Andalas University, Kampus \\ Limau Manis, Padang 25163, Indonesia
}

(Received: January 2017 / Revised: June 2017 / Accepted: November 2017)

\begin{abstract}
Due to increased environmental sensitivity, renewable-based lubricants, and food grade lubricants are being considered potential alternatives to petroleum-based lubricants. Understanding of bio-lubricant in relation to abrasive wear is essential for using ball bearings in industrial implementation. This study focused on wear mechanism on ball bearings lubricated by bio-lubricants. Palm oil and coconut oils were used in this study. Coconut oils were made by two processes, namely dry and wet processing, resulting in three types of oil (virgin coconut oil [VCO], refined coconut oil [RCO], and hydrogenated coconut oil [HCO]). Full-scale bearing life tests were conducted with $300 \mathrm{~N}$ load with 2,840 rpm for 6 hours. Method of lubrication was circulating oil by using pump injection to the self-aligning ball bearings. The results show that the main wear mechanism, which impacted on the surfaces of inner race, outer race, and ball for different bio-lubricants, were abrasive and adhesive wear. It found that the abrasion rate was the least severe for VCO. The discrepancies of worn surfaces are thought to be as a result of the physical and chemical properties of bio-lubricants.
\end{abstract}

Keywords: Abrasive wear; Ball bearing; Bio-lubricant; Coconut oils; Palm oil

\section{INTRODUCTION}

Vegetable oils have received the most attention as an attractive alternative to mineral based lubricants (Honary, 2001) due to several useful physical properties. Bio-based lubricants have a higher lubricity, a high flash point, a relatively stable viscosity index, and are non-toxic and biodegradable. Therefore, bio-based lubricants are used in many environmentally sensitive industrial applications, such as food industry, agricultural machinery, and machines near water.

Nowadays, the amount of research into bio-based lubricants has drastically increased due to environmental awareness. Most of research focused on improving physical properties of biobased lubricant through bio-engineering, chemical process, blended bio-lubricant (Pavani et al., 2017), and the use of additives. Research on vegetable oil has been conducted by Gasni et al. (2006) to investigate tribological properties of coconut oil and palm oil by using pin on disc test apparatus. The research of using bio-lubricant on ball bearings is still limited. However, the wear mechanism in ball bearings has been investigated by Zhang et al. (2006). They conducted an experiment on ball bearings to investigate wear due to lubricant failure. The lubricant failure occurred on contact because of contaminant. In 2009, Dwyer Joyce investigated wear mechanism on ball bearings due to solid particles in lubricant. The particles damage the bearing surfaces by tree-body abrasion. This paper demonstrated wear mechanism in rolling element

\footnotetext{
*Corresponding author's email: dedison.gasnisheff@yahoo.co.uk, Tel.+62-751-72497, Fax.+62-751-72566 Permalink/DOI: https://doi.org/10.14716/ijtech.v8i7.688
} 
bearing using coconut oils and palm oil as lubricant. As the bearing failed during the experiment, the surface textures of the inner race, outer race, and ball bearing were examined. The results of experiment are used to explain the wear mechanism occurred on inner, outer, and ball of ball bearings with different bio-lubricants. The grease lubricant that has the same basic lubricant viscosity with bio-lubricant was used in this study as comparison.

\section{METHODS}

\subsection{Lubricants and Material}

Coconut oils and palm oil were used in this study as lubricant. There are three kinds of coconut oils used in this study with different extraction methods, namely wet and dry processing, resulting in virgin coconut oil (VCO) and hydrogenated coconut oil (HCO) from the wet process and refined coconut oil (RCO) from the dry process. Samples of biolubricants were obtained from local market. The physical properties and fatty acid contained of the vegetable oil are shown in Table 1 and Table 2, respectively.

Table 1 Physical properties of vegetable oils (Gasni et al., 2015)

\begin{tabular}{lrccc}
\hline \multirow{2}{*}{ Parameter } & \multicolumn{3}{c}{ Coconut oils } & \multirow{2}{*}{ Palm oil } \\
\cline { 2 - 4 } & VCO & HCO & RCO & \\
\hline Viscosity at & 25.82 & 26.44 & 26.58 & 40.10 \\
$40^{\circ} \mathrm{C}$, cSt & 5.664 & 5.391 & 5.760 & 8.931 \\
Viscosity at & 169.13 & 143.88 & 167.59 & 213.13 \\
$100^{\circ} \mathrm{C}$, cSt & 309.5 & 307.5 & 303.5 & 305.5 \\
Viscosity Index & & & \\
Flash Point & &
\end{tabular}

Table 2 Fatty acids contained of vegetable oils

\begin{tabular}{cccccccc}
\hline $\begin{array}{c}\text { Fatty } \\
\text { acid (\%) }\end{array}$ & $\mathrm{C} 10: 0$ & $\mathrm{C} 12: 0$ & $\mathrm{C} 14: 0$ & $\mathrm{C} 16: 0$ & $\mathrm{C} 18: 0$ & $\mathrm{C} 18: 1$ & $\mathrm{C} 18: 2$ \\
\hline VCO & 10.81 & 68.7 & 15.3 & 2.77 & 0.57 & 0.97 & 0.24 \\
HCO & 6.45 & 48.61 & 17.48 & 8.45 & 2.65 & 6.30 & 1.59 \\
RCO & 6.82 & 49.98 & 17.61 & 8.45 & 2.57 & 5.82 & 1.37 \\
Palm oil & 6.89 & 49.95 & 17.17 & 8.07 & 2.34 & 6.04 & 1.43 \\
\hline
\end{tabular}

Table 3 Physical properties of commercial grease

\begin{tabular}{lc}
\hline \multicolumn{1}{c}{ Designation } & Synthetic grease \\
\hline Soap type & Lithium \\
Base oil type & Polyalphaolevin Synthetic Oil (PAO) \\
Base oil viscosity: at $40^{\circ} \mathrm{C}, \mathrm{cSt}$ & 18 \\
Base oil viscosity: at $100^{\circ} \mathrm{C}, \mathrm{cSt}$ & 4.5 \\
\hline
\end{tabular}

Commercial synthetic grease was used as comparison and the grease was obtained in local market. The physical properties of the grease are shown in Table 3. A double row self- 
aligning ball bearing was used in this study. The diameter of bearing is $62 \mathrm{~mm}$ and the shaft diameter is $30 \mathrm{~mm}$.

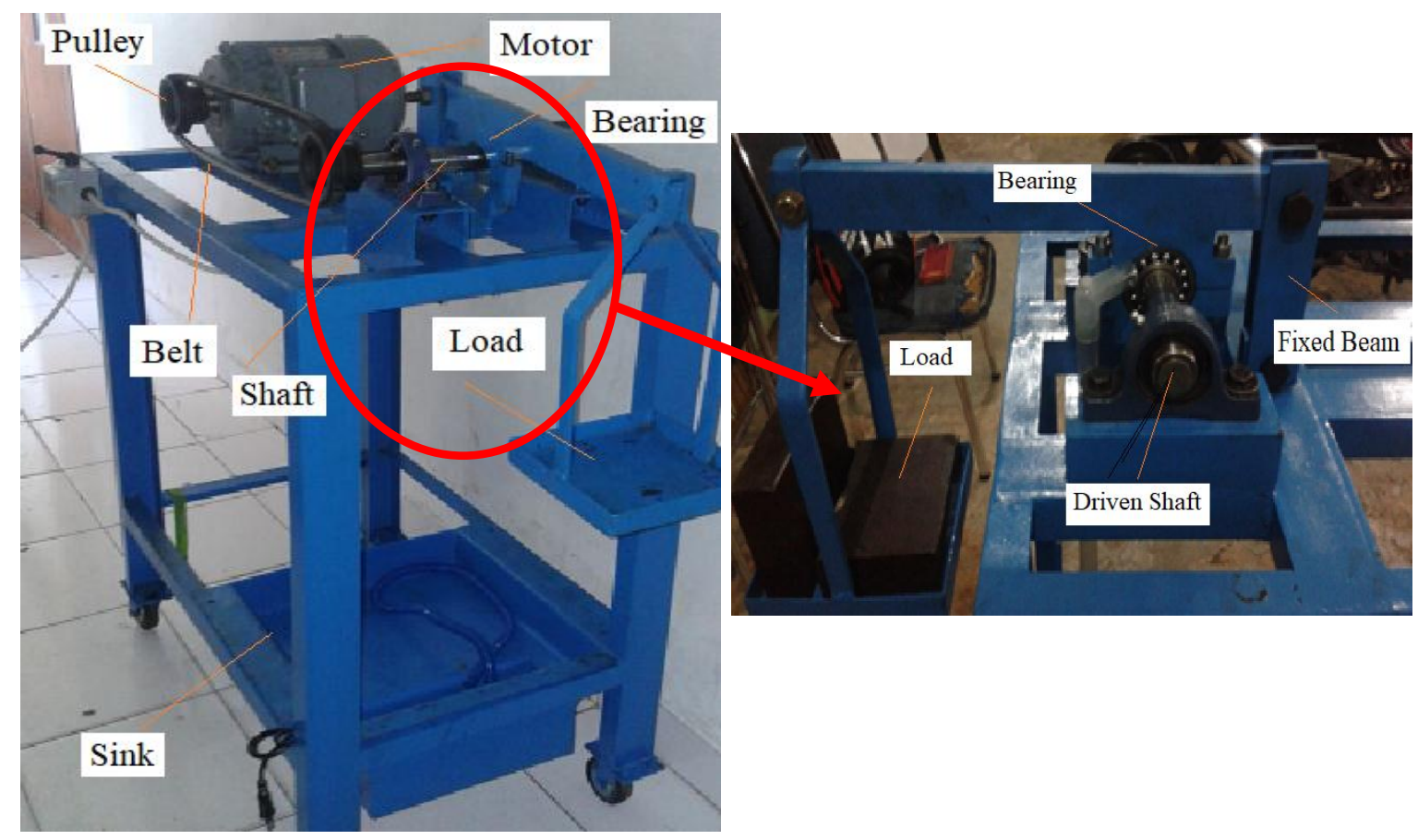

(a)

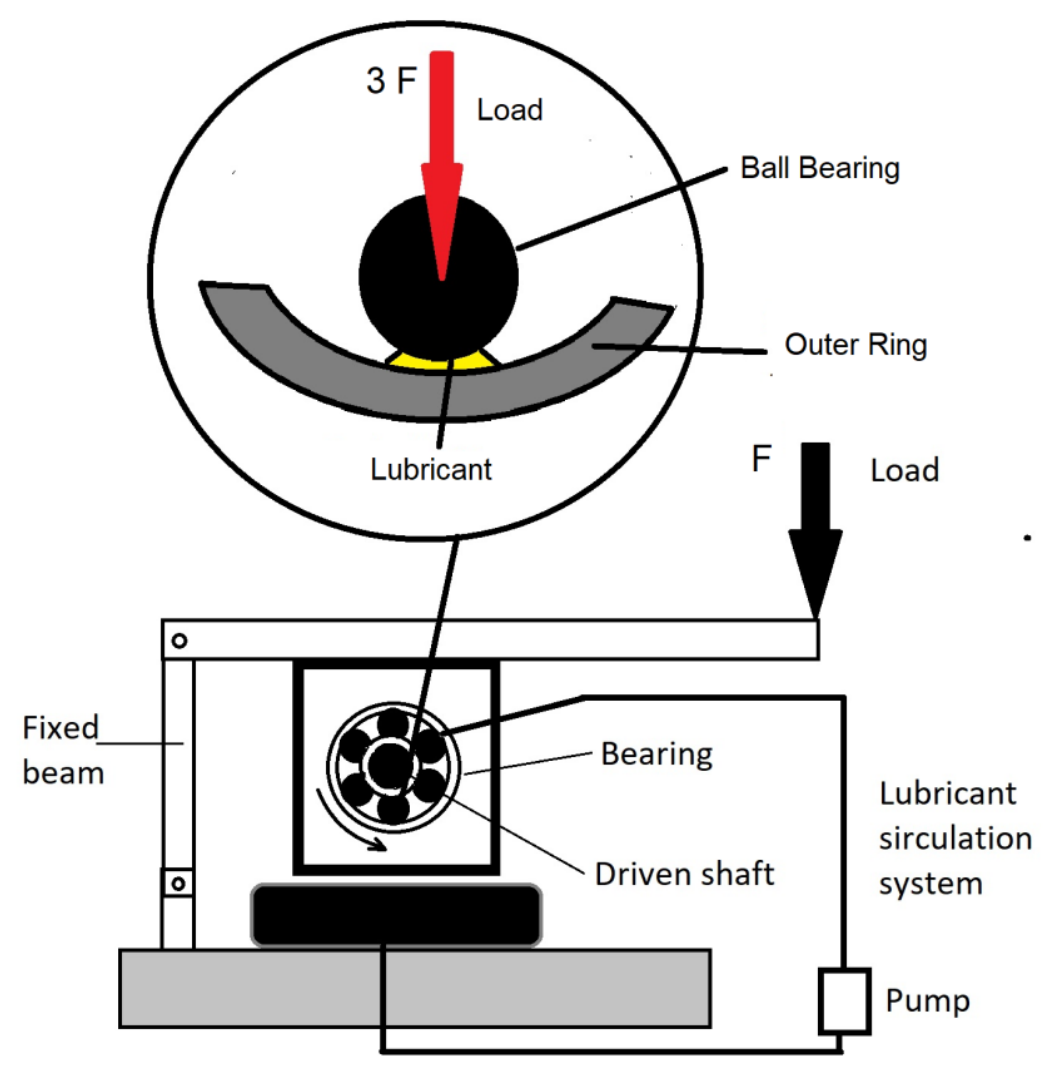

(b)

Figure 1 (a) Ball bearing wear apparatus; and (b) schematic diagram of ball bearing test rig 


\subsection{Apparatus}

In the present investigation, a ball bearing wear apparatus had been used to investigate wear occurred on ball bearings. The ball bearings wear apparatus consisted of a rotating shaft of $30 \mathrm{~mm}$ diameter supported on two deep groove ball bearings and a self-aligning ball bearing. As shown in Figure 3, two deep groove ball bearings were fitted to the ends of the shaft and fixed into rigid housings. Radial load was applied on a self-aligning ball bearing.

\subsection{Procedures}

A ball bearing wear apparatus was used as shown in Figure 1. Tangential load of $300 \mathrm{~N}$ was applied on a self-aligning ball bearing with $2,850 \mathrm{rpm}$ rotational speed and a $1.5 \mathrm{~kW}$ electric motor. Test was conducted for 6 hours or equal to one million rotations of ball bearings. Vegetable oil lubricants were injected to bearing by using pump to circulate the oil, whereas the grease was applied on the bearings. The wear occurred on the inner race, outer race, and ball of ball bearings themselves, which were examined by using an optical microscope and scanning electron microscope (SEM).

\section{RESULTS AND DISCUSSION}

\subsection{Surface Texture Analysis for Different Bio-Lubricants}

Based on Hertzian contact theory (Johnson, 1985), when two non-conforming solids (ball and inner or outer ring) under pressure of geometrically ideal shapes are brought into contact, the initial contact is a point or an ellipse. Due to the contact pressure, the normal load causes principal stresses and shear stresses beneath in the contact pressure. The maximum shear stress occurs below the surface at a depth of 0.48 times radius of contact. To minimize effect of contact pressure, lubricant is applied to contact area to separate two contact bodies. In this experiment, method of lubrication used continuous feed deep lubricant by using a pump. The failure of the rolling elements of a bearing is frequently associated with lubrication failure. The area of the contact presure results in an adequate separation of the rolling elements and raceways leading to wear and contact fatigue. To replicate these failure mechanisms in the laboratory, the experiment was conducted by varied of coconut oils and palm oil as lubricant for 6 hours with $300 \mathrm{~N}$ loads and 2,500 rpm rotational speed.

Figures 2 and 3 reveal the path of the pattern of wear that occurred on inner race and outer race, respectively. The appearance of the pattern prove that, for the wear that occured on the surface of the inner and outer race, the main wear mechanisms were abrasive and adhesive wear. The path patterns of worn from the inner race tended to be uniform in width whereas those of outer race tended to be not uniform. The width of the path pattern among bio-lubricant was vary. The variation of worn surfaces of inner and outer race was not caused by physical properties of bio-lubricant. In this case where viscosity of palm oil is higher than that of coconut oil as shown in Table 1, but its scar width of the outer race was higher than those of HCO and VCO as shown in Figure 4.

In contrast with investigation results of Gasni and Rahmat (2017) for ball bearings at high speed, the lubrication regime of ball bearings is operated on elastohydrodynamic lubrication (EHL) regime as shown in Figure 5. In EHL regime, the film thickness separating the ball from the inner race or outer race is only influenced by viscosity of lubricant. So, the discrepancies of worn surfaces were influenced not only by physical properties but also by chemical composition of bio-lubricants where fatty acid contained in bio-lubricants are varied as shown in Table 2. According to Table 2, the fatty acids of the coconut and palm oils were relatively similar. Investigation was conducted by Fox et al. 
(2004) and Siniawsky et al. (2007) find that the fatty acid within sunflower oil plays a role in protecting sliding surfaces. Saturated acids contained in the oil have the ability to provide surface protection at the level of intermolecular interaction.
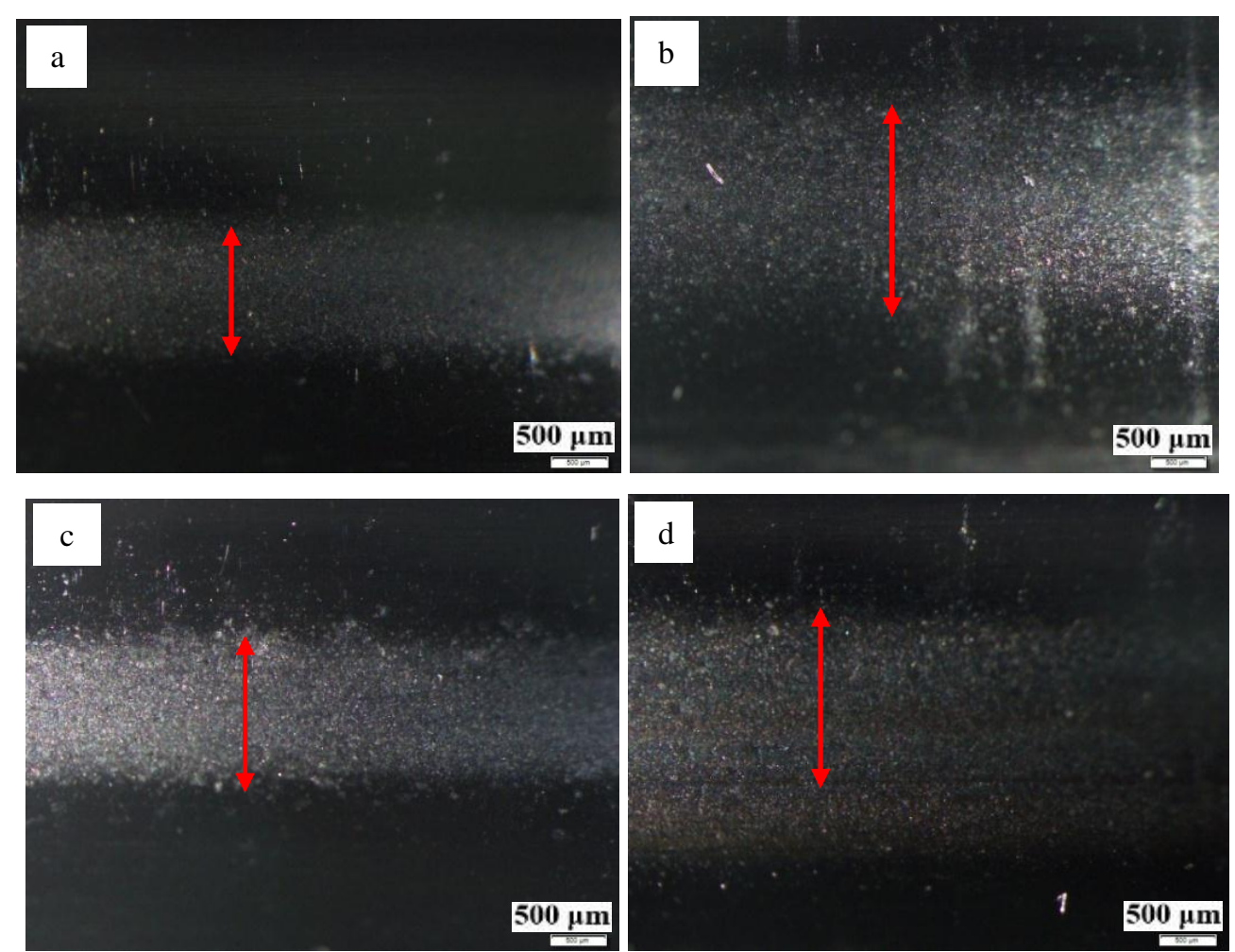

Figure 2 Optical images of the surface texture of inner race for different bio-lubricants (a) RCO (b) Palm oil (c) HCO, and (d) VCO
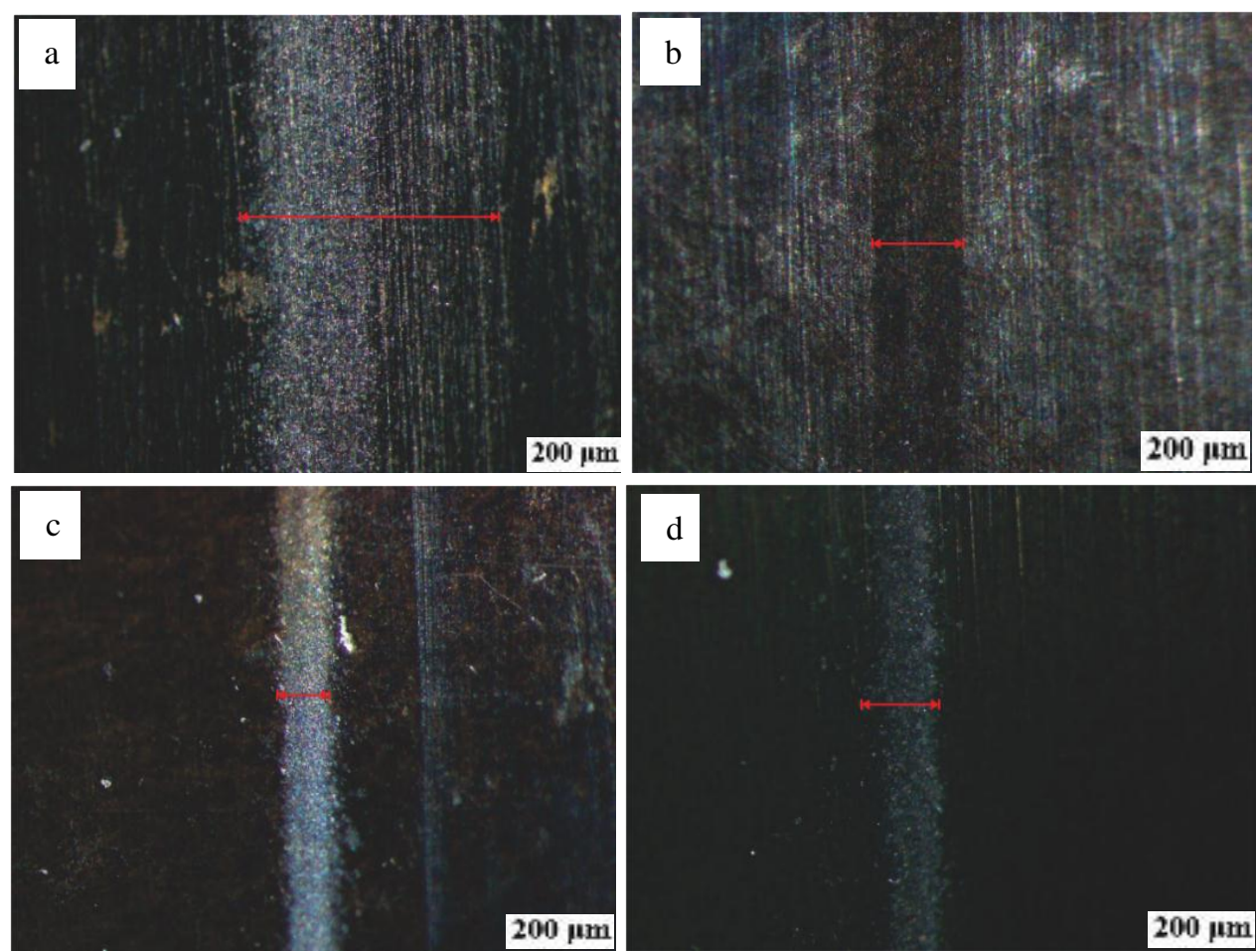

Figure 3 Optical images of the surface texture of outer race for different bio-lubricants (a) RCO (b) Palm oil (c) HCO, and (d) VCO 


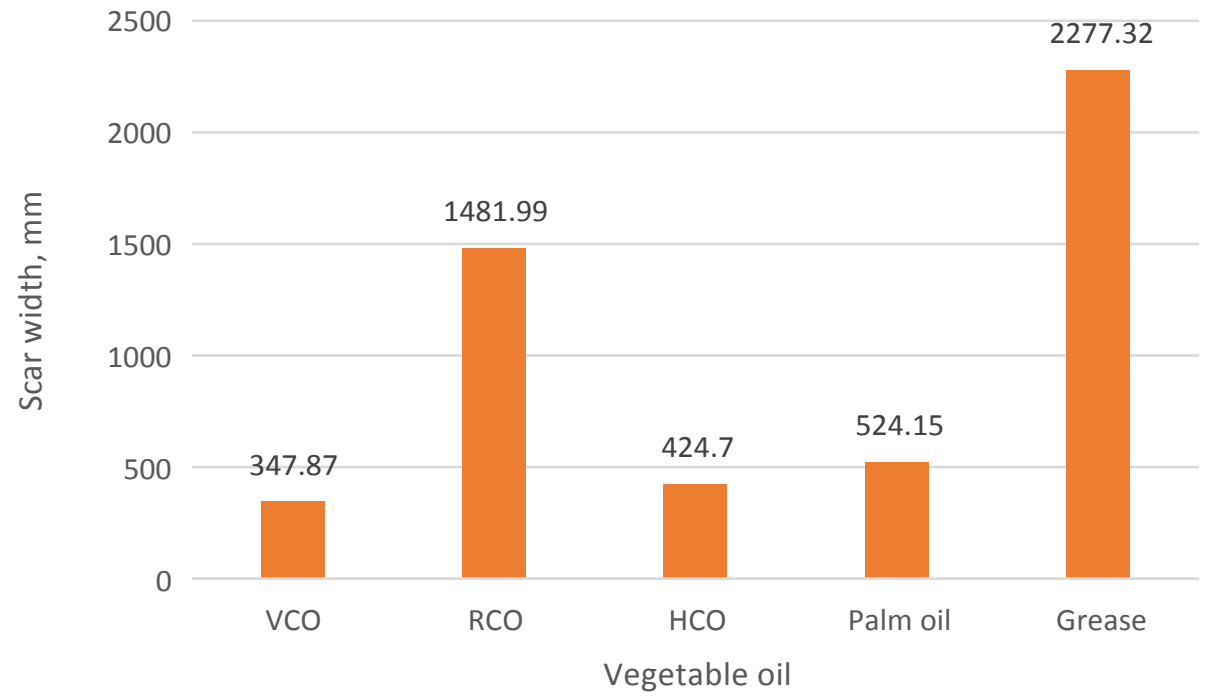

Figure 4 Comparison of scar width of outer race bearing for different vegetable oils

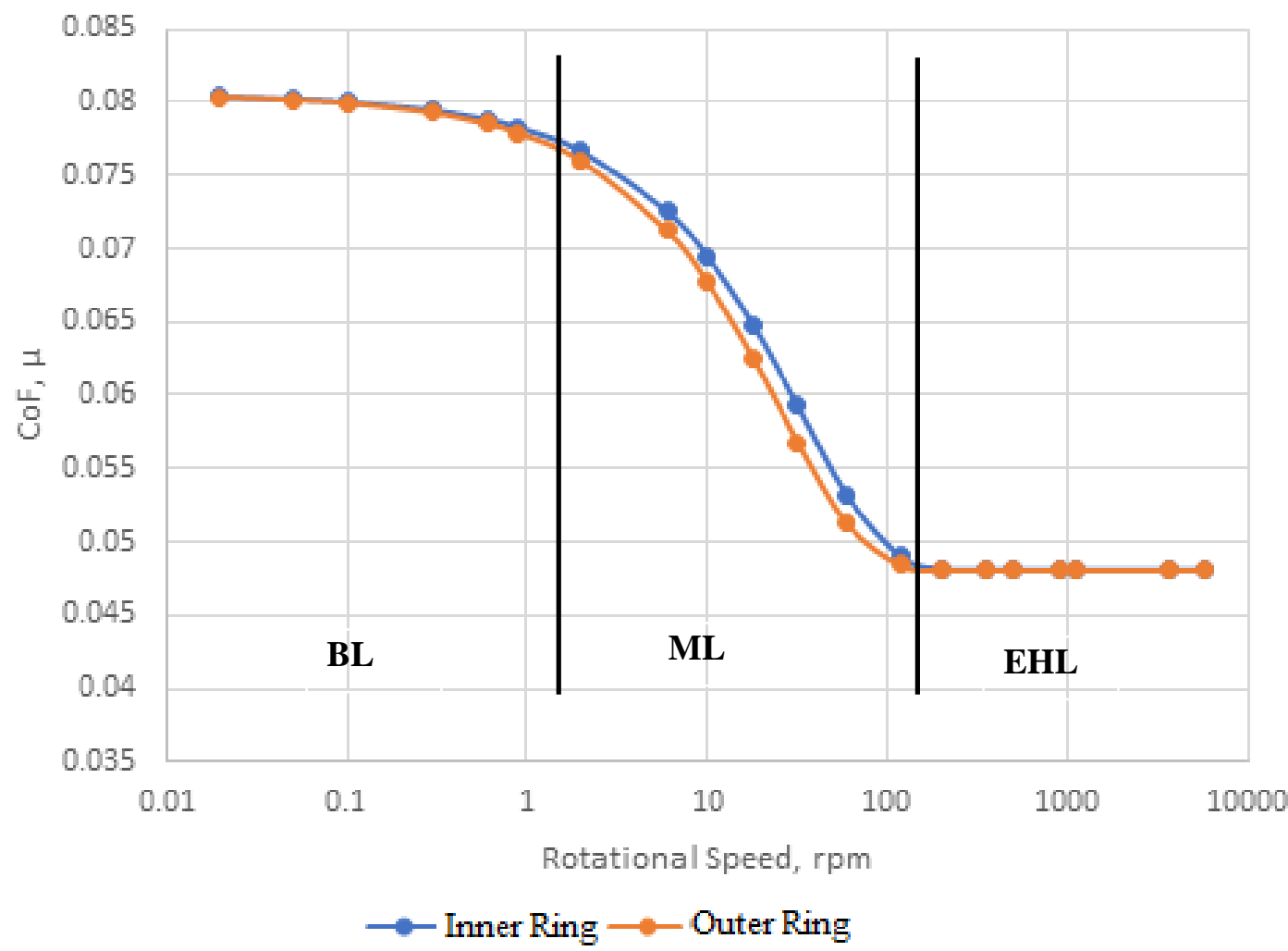

Figure 5 Regime lubrication of ball bearing, boundary lubrication (BL), mixed lubrication (ML), and elastohydrodynamic lubrication (EHL) adopted from Gasni and Rahmat (2017)

In the rolling elements, some of the same oil is ejected from the raceways and some of the oil is lost because of centrifugal action. This causes in a reduction of the thickness lubricant in contact area, so the contact is occurred between solid and solid. Inspection revealed the wear surface of the outer race and ball observed in the SEM images under various type of bio-lubricants (Figures 6 and 7). 

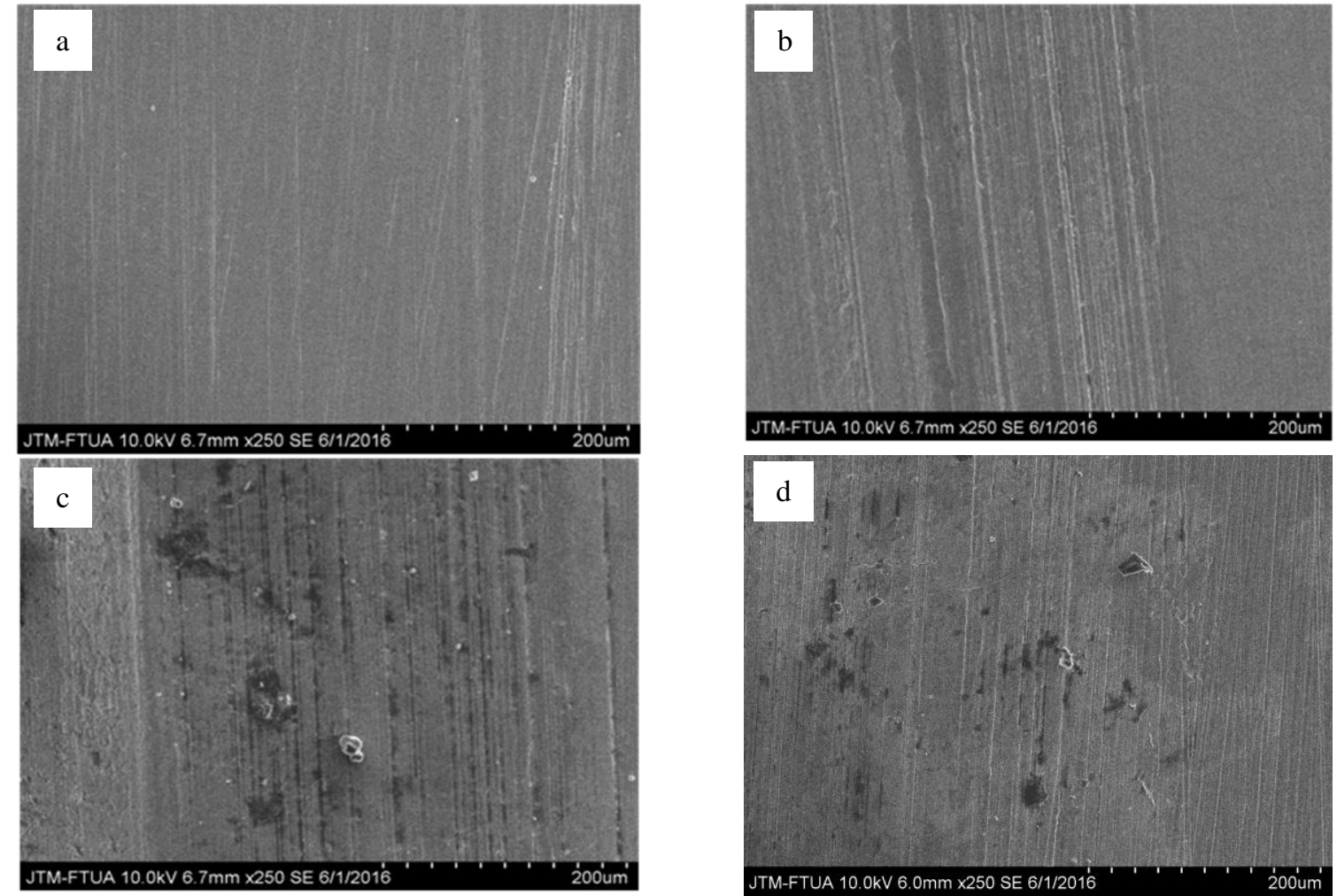

Figure 6 Comparison of outer race SEM morphology with varies vegetable oil lubricants: (a) RCO; (b) Palm oil; (c) HCO; and (d) VCO
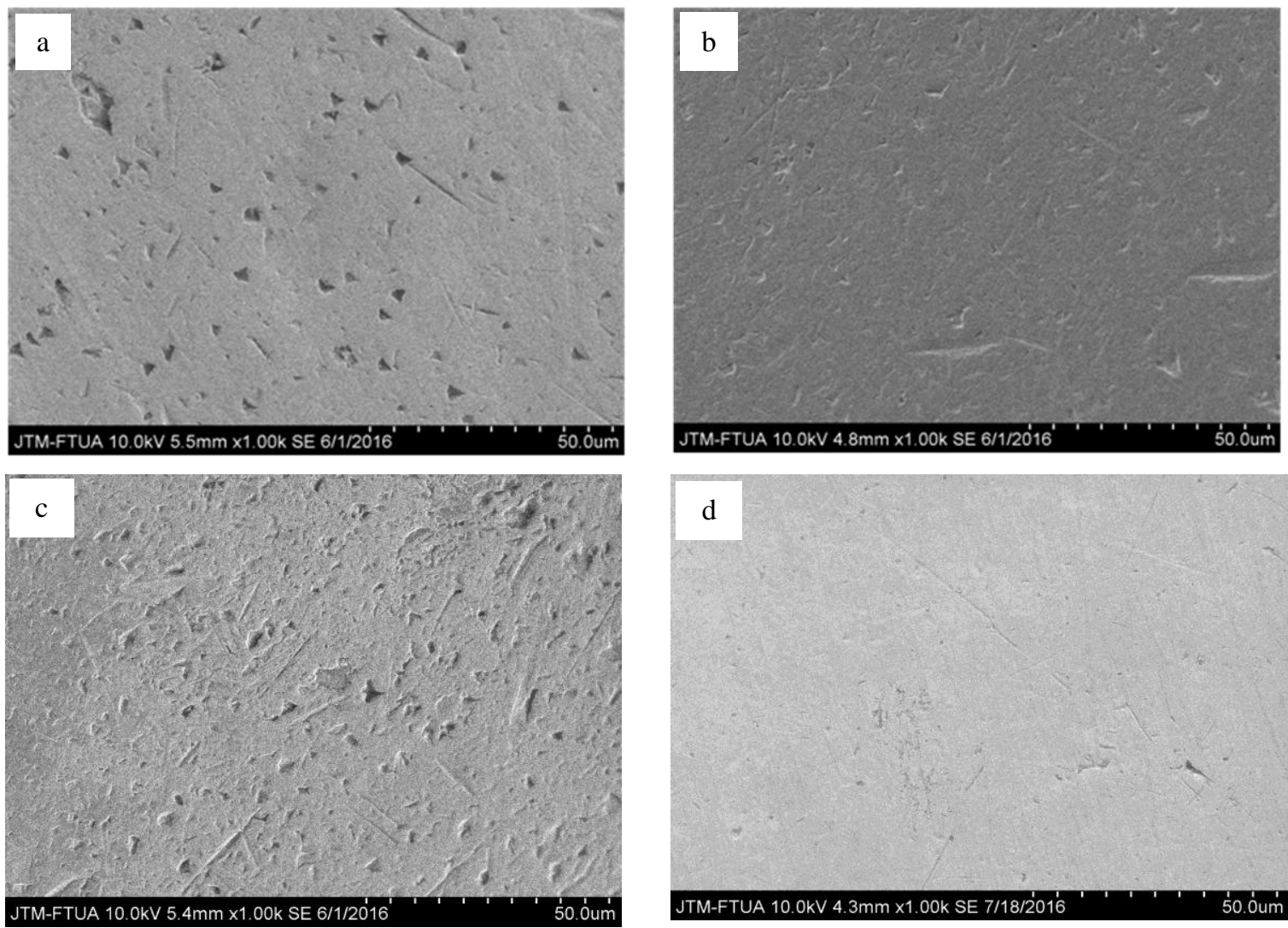

Figure 7 SEM images of ball bearing under various bio-lubricant: (a) RCO; (b) Palm oil; (c) HCO; and (d) VCO 
Referring to Figure 6, it found that severe wear occurred on the surface of the outer race for bio-lubricants HCO and VCO (Figures $6 \mathrm{c}$ and $6 \mathrm{~d}$ ). Reduction of lubricant film thickness leads to the surfaces to come closer to each other to cause higher wear. Reduction of lubricant was caused by starvation. Starvation can occur on in rolling bearing if the time between subsequent events of contact between rolling elements and raceways is too short for ensuring a sufficient replenishment of lubricant to support fully flooded condition (Dowson, 1995; Spikes \& Olver, 2003). The wear SEM images of the ball are consistent with the wear SEM images of the outer race of ball bearing as shown in Figures 6 and 7. Observation of the wear on the ball by using SEM provides insight as to wear mechanism. The adhesive wear was primary mechanism observed on the surface of ball. Figures 6 and 7 show that the observed wear on the ball, in the form of missing ball material, was minor. This is consistent with investigation results of Hanrahan et al. (2015).

\subsection{Surface Texture for Grease}

The grease lubricated bearings are generally running under starved lubrication conditions (Lugt, 2009). Solid-to-solid contact due to starvation form local stress raisers (Harris \& Barnsby, 2001). Furthermore, may take place in contacts between rough surfaces, for instance as microabrasion (or sliding micro-fatigue) between rolling elements. Micro abrasive and sliding fatigue in the micro-slip regions of rolling contacts are responsible for part of the surface of alterations, for rolling contact wear, and for wear particle formation in the running-in in rolling bearings (Ollofsson et al., 2000). Figures 8 and 9 show the images of surface texture of outer and inner race with grease lubrication. The severe wear and rolling contact fatigue occurred on the surface of inner race and outer race due to excessive load. The scare width of outer race reached $2277.32 \mathrm{~mm}$ as shown in Figure 4 which is followed by vibration. As mentioned previously, the initial film thickness is higher than can be expected based on the base oil viscosity only. After some time, starvation occurs where the film is reduced in thickness. This is caused replenishment of the grease in the running track is too slow to give any significant effect of lubrication. Solid to solid contact could occurs, which causes wear on the surface of the inner, outer, and ball bearings.
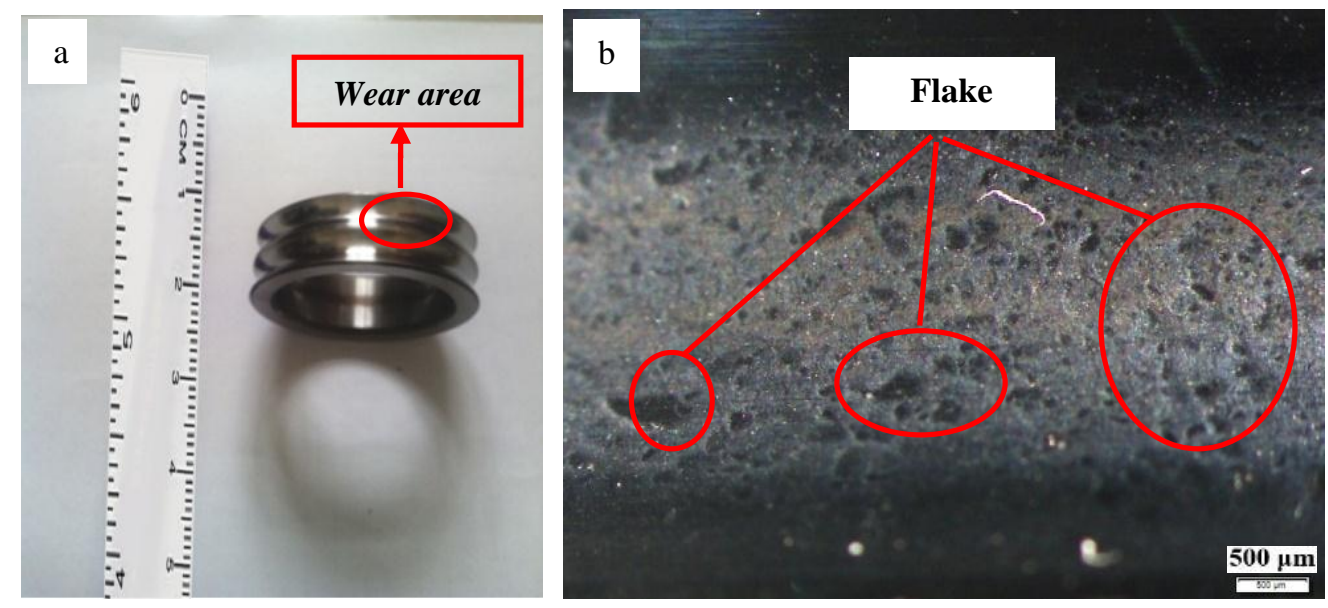

Figure 8 Images of surface texture of inner race wear with synthetic grease: (a) wear area; (b) wear mechanism

In rolling bearing, the impact load resulting from the dynamic loading occurring on a bearing excites vibration. The plastic deformation caused by abrasion and the micro cracking caused by fatigue are weak sources of vibrations. After the running-in stage, most of the operational lifetime of a rolling bearing is supposed to occur under steady-state conditions. The operating conditions during the steady-state phase will finally determine 
whether the bearing will be subject to rolling contact wear only or if the contact mechanism will develop into a process rolling contact fatigue. In the last stage of rolling contact fatigue of bearing can be divided into two periods (Choi \& Liu, 2007). The first period shows no significant change in the vibration amplitude, as the crack initiation and propagation occur below the surface. The second period shows a significant increase in vibration amplitude, due to the formation and progress of spalling on the surface, as shown in Figures $8 b$ and $9 b$. By that time, the running conditions of the bearing has evolved into a stage of progressive pitting and failure development. The acceleration of the fatigue and pitting process is signified by an increase in the vibration level, rate of wear particle formation, and wear particle size (Day, 1996).
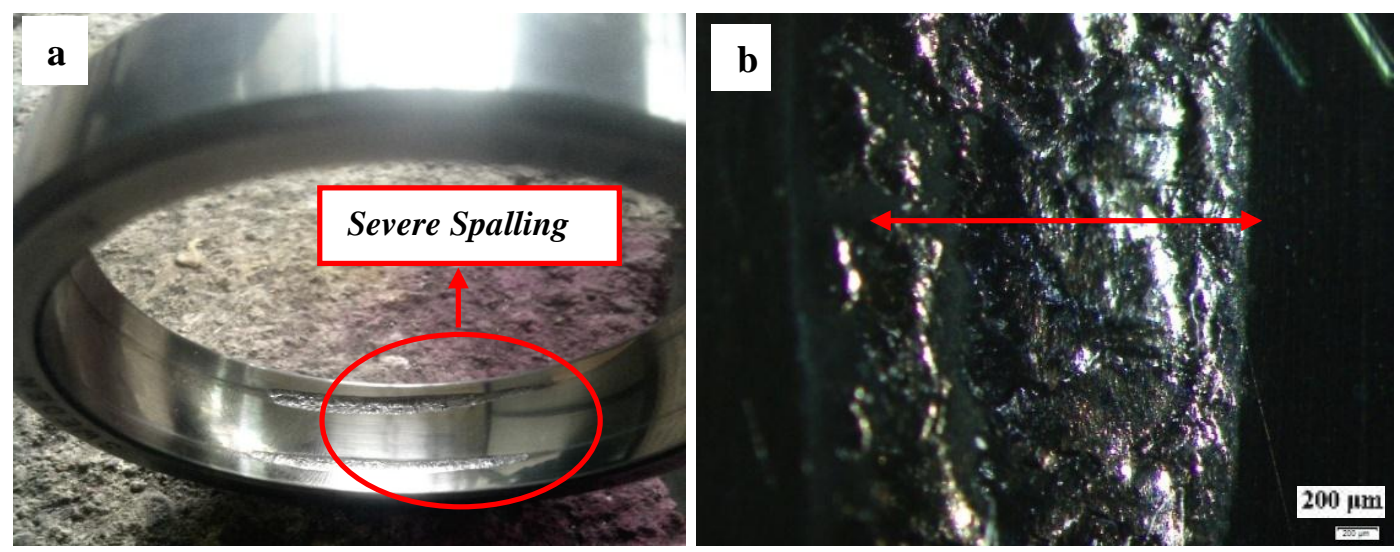

Figure 9 Images of surface texture of outer race wear with synthetic grease: (a) wear area;

(b) wear mechanism

\section{CONCLUSION}

During the operation, rolling contact wear and rolling contact fatigue were occurred on ball bearing. After 6 hours operation with $2850 \mathrm{rpm}$ of shaft rotations and $300 \mathrm{~N}$ radial load, the wear formation on the surface of inner race, outer race, and ball was varied with different bio-lubricants. The mechanisms of wear on the bearing were abrasive and adhesive wear. In the ball, the adhesive wear mechanism was very dominant. The wear phenomena for different bio-lubricants on ball bearings were complicated, because lubrication regime in the ball bearings is EHL where viscosity of lubricant is very important, the palm oil is not sufficiently viscose in the case. Thefore, the wear that occurred on the surface of the inner race, outer race, and ball bearing was influenced not only by the physical properties of the lubricant but also by its chemical properties. The important chemical property of the bio-lubricant is fatty acids, which account for lower abrasion. The abrasion rate is smaller for VCO than the other lubricants tested, as it has a high lauric acid (C12:0) content.

From the experiment results, the vegetable oil lubricants were good lubricity compared with the grease lubricant. The worn surface resulting from using the grease lubricant was very severe. It is caused that the starvation phenomenon was occurred on ball bearing because film thickness was reduced in thickness.

\section{ACKNOWLEDGEMENT}

The authors are grateful for the financial supported by Directorate of Higher Education of Republic of Indonesia through the Fundamental Research Scheme with contract No. 14/H.16/FUNDAMENTAL/LPPM/2015 and No. 31/UN.16/FD/LPPM/2016 and Research Scheme of Mechanical Engineering Department Andalas University 2017. 


\section{REFERENCES}

Choi, Y., Liu, C., 2007. Spall Progression Life for Rolling Contact Verified by Finish Hard Machined Surfaces. Wear, Volume 262(1-2), pp. 24-35

Day, M.J., 1996. Condition of Monitoring of Hydraulic System. In: Handbook of condition monitoring (Ed. B.K.N. Rao), Elsevier Advanced Technology, Oxford, UK

Dowson, D., 1995. Elastohydrodynamic and Micro-hydrodynamic Lubrication. Wear, Volume 190, pp. 125-138

Dwyer-Joyce, R.S., 2009. Predicting the Abrasive Wear of Ball Bearing by Lubricant Debris. Wear, Volume 233-235, pp. 692-701

Gasni, D., Mulyadi, I.H., Affi, Jon, 2015. Comparison of Physical and Tribological Properties of Coconut Oils Extracted from Dry and Wet Processing. In: Proceedings of Malaysian Tribology Conference, pp. 217-219

Gasni, D., Rahmat, S., 2017. Determining the Lubrication Regime on the Ball Bearings using the Stribeck Curve (Menentukan regime pelumasan pada ball bearing dengan menggunakan kurva Stribeck). Jurnal METTEK, Volume 3(1), pp. 21-28

Fox, N.J., Tyrer, B., Stachowiak, G.W., 2004. Boundary Lubrication Performance of Free Fatty Acids in Sunflower Oil. Tribology Letters, Volume 16(4), pp. 275-281

Honary, L.A.T., 2001. Biodegradable Biobased Lubricants and Greases. Machinery Lubrication Magazine, Issue Number: 200109

Harris, T.A., Barnsby, R.M., 2001. Life Rating of Roller Bearing. Proceedings of the Institution of Mechanical Engineers, Part J: Journal of Engineering Tribology, Volume 2015(6), pp. 577-595

Hanrahan, B., Misra, S., Waits, C.M., Ghodssi, R., 2015. Wear Mechanisms in Microfabricated Ball Bearing System. Wear, Volume 326, pp. 1-9

Johnson, K., 1985. Contact Mechanics, Cambridge university press, Cambridge, UK

Ollofsson, U., Andersson, S., Björklund, S., 2000. Simulation of Mild Wear in Boundary Lubricated Spherical Roller Trust Bearings. Wear, Volume 241(2), pp. 180-185

Lugt, P.M., 2009. A Review on Grease Lubrication in Rolling Bearings. Tribology Transaction, Volume 52(4), pp. 470-480

Pavani, P.N.L., Pola Rao, R., Prasad, C.L.V.R.S.V., 2017. Synthesis and Experimental Investigation of Tribological Performance of a Blended (Palm and Mahua) Biolubricant using the Taguchi Design of Experiment (DOE). International Journal of Technology, Volume 8(3), pp. 418-427

Spikes, A.H., Olver, A.V., 2003. Basic of Mixed Lubrication. Lubrication Science, Volume 16(1), pp. 1-28

Siniwsky, M.T., Saniei, N., Adhikari, B., Doezema L.A., 2007. Influence of Fatty Acid Composition on the Tribological Performance of Two Vegetable-based Lubricants. Lubrication Science, Volume 24(2), pp. 101-110

Zhang, J., Drinkwater, B.W., Dwyer-Joyce, R.S., 2006. Monitoring of Lubricant Film Failure in a Ball Bearing using Ultrasound. Journal of Tribology, Volume 128(3), pp. 612-618 